American Journal of Environmental Sciences 6 (2): 124-129, 2010

ISSN 1553-345X

(C) 2010 Science Publications

\title{
In-Cylinder Heat Transfer Characteristics of Hydrogen Fueled Engine: A Steady State Approach
}

\author{
${ }^{1,2}$ M.M. Rahman, ${ }^{1}$ Khalaf I. Hamada, ${ }^{1}$ M.M. Noor, ${ }^{1}$ Rosli A. Bakar, \\ ${ }^{1}$ K. Kadirgama and ${ }^{3}$ M.A. Maleque \\ ${ }^{1}$ Department of Mechanical Engineering, University Malaysia Pahang, \\ ${ }^{2}$ Automotive Excellence Center, University Malaysia Pahang, \\ 26600 Pekan, Kuantan, Pahang, Malaysia \\ ${ }^{3}$ Department of Manufacturing and Material, Engineering, Faculty of Engineering, \\ International Islamic University Malaysia, Gombak, Selangor, Malaysia
}

\begin{abstract}
This study presents in-cylinder heat transfer characteristics of a single cylinder port injection Hydrogen fueled Internal Combustion Engine $\left(\mathrm{H}_{2} \mathrm{ICE}\right)$ using a steady state approach. Problem statement: The differences in characteristics between hydrogen and hydrocarbon fuels are led to the difference in the behavior of physical processes during engine cycle. One of these processes is the in-cylinder heat transfer. Approach: One dimensional gas dynamic model was used to describe the heat transfer characteristics of the engine. The engine speed was varied from 2000-5000 rpm, crank angle from $-40^{\circ}$ to $+100^{\circ}$, while Air-Fuel Ratio (AFR) was changed from stoichiometric to lean limit. Results: The simulated results showed higher heat transfer rate but lower heat transfer to total fuel energy ratio with increasing the engine speed. The in-cylinder pressure and temperature were increased with decreasing AFR and increasing engine speed. The in-cylinder air flow rate was increased linearly with increasing engine speed as well as air fuel ratio. Conclusion/Recommendations: The results showed that the AFR has a vital effect on characteristics variation while the engine speed has minor effect. These results can be utilized for the study of combustion process, fuel consumption, emission production and engine performance.
\end{abstract}

Key words: Hydrogen fuel, heat transfer rate, port injection, engine speed, air fuel ratio

\section{INTRODUCTION}

Hydrogen, as an alternative fuel, has the unique properties which provides a significant advantages over other types of fuel. It can be used as a vehicle fuel which is promising in the effects of establishes an environmental friendly mobility system. Extensive studies were performed on hydrogen fueled internal combustion engines (White et al., 2006; Kahraman et al., 2007; Rahman et al., 2009a; 2009b). The increasing concern of energy shortage and environmental protection, research are going on for improving engine fuel economy. Hydrogen engine is being developed into a hydrogen fueled engine with different types of fuel supply method (Kahraman et al., 2007; Rahman et al., 2009a; Bakar et al., 2009). It is particularly suitable for fueling internal combustion engines (Yusaf et al., 2005). The flow field identification inside a cylinder of internal combustion engines during the intake, compression, expansion and exhaust strokes are an important stage for comprehension of physical phenomenon which occurs in the motor cycle. The movement of the inlet air-fuel mixture has a great influence on the performance of the engine. Developments in the engine simulation technology have made the virtual engine model a realistic suggestion (Li et al., 2000). Now-a-day, computational fluid dynamics codes are used to simulate the engine performance and visualize the flow characteristics (Bahram et al., 1994). Application of these codes for engine improvement have saved significant time and cost in the design and development stage of combustion engine system (Shojaeefard and Noorpoor, 2008). Computational modeling and analysis of in-cylinder gas flow is a major part of successful combustion, emission production and engine

Corresponding Author: M.M. Rahman, Automotive Excellence Center, Faculty of Mechanical Engineering,

University Malaysia Pahang, 26600 Pekan, Kuantan, Pahang, Malaysia

Tel: 6094242246 Fax: 6094242202 
performance simulation. Realization of the in-cylinder gas flow characteristics for the internal combustion engine is very substantial for advanced understanding and further optimization of the engine. The in-cylinder gas flow characteristics have major influence on combustion process, fuel consumption, emission production and engine performance. The objective of this study is to investigate the variation of in-cylinder heat transfer characteristics of port injection hydrogen fueled internal combustion engine by utilizing steady state method. The effect of engine speed and AFR are also investigated.

\section{MATERIALS AND METHODS}

Engine model: A single cylinder port injection hydrogen fuel model was developed utilizing the GTsuite software. The injection of hydrogen was studied in the midway of the intake port. The computational model of single cylinder hydrogen fueled engine is shown in Fig. 1. The engine specifications are listed in Table 1. The intake and exhaust ports of the engine cylinder are modeled geometrically with pipes and the air enters through a bell-mouth orifice to the pipe. The discharge coefficients of the bell-mouth orifice were set to 1 to ensure the smooth transition. The diameter and length of bell-mouth orifice pipe are 0.07 and $0.1 \mathrm{~m}$ respectively and it is connected to intake air cleaner with $0.16 \mathrm{~m}$ of diameter and $0.25 \mathrm{~m}$ of length. A $\log$ style manifold was developed from a series of pipes and flow-splits. The total volume of each flow-split was $256 \mathrm{~cm}^{3}$. The flow-splits compose from an intake and two discharges. The intake draws air from the preceding flow-split. One discharge supplies air to adjacent intake runner and other supplies air to the next flow-split. The last discharge pipe was closed with a cup. The flow-splits are connected with each other through pipes with $0.09 \mathrm{~m}$ diameter and $0.92 \mathrm{~m}$ length. The junctions between the flow-splits and the intake runners were modeled with bell-mouth orifice.

The intake runners were linked to the intake ports with $0.04 \mathrm{~m}$ diameter and $0.08 \mathrm{~m}$ length. The temperature of the piston is higher than the cylinder head and cylinder block wall temperature. Heat transfer multiplier is used to take into account for bends, additional surface area and turbulence caused by the valve and stem. The pressure losses are included in the discharge coefficients calculated for the valves and no additional pressure losses were used because of wall roughness. The exhaust runners were modeled as rounded pipes with $0.03 \mathrm{~m}$ inlet diameter and $80^{\circ}$ bending angle for runners $1-4$ and $40^{\circ}$ bending angle of runners 2 and 3. Runners 1-4 and runners 2 and 3 are connected before enter in a flow-split with $169.646 \mathrm{~cm}^{3}$ volume. Conservation of momentum is solved in 3dimentional flow-splits even though the flow based on a one-dimensional version of the Navier-Stokes equation.

\begin{tabular}{lrl} 
Table 1: Engine specification & & \\
\hline Engine parameter & Value & Unit \\
\hline Bore & 100.0 & $\mathrm{~mm}$ \\
Stroke & 100.0 & $\mathrm{~mm}$ \\
Total displacement & 3142.0 & $\mathrm{~cm}^{3}$ \\
Connecting rod length & 220.0 & $\mathrm{~mm}$ \\
Compression ratio & 9.5 & \\
Intake valve close, IVC & -96.0 & ${ }^{0} \mathrm{CA}$ \\
Exhaust valve open, EVO & 125.0 & ${ }^{0} \mathrm{CA}$ \\
Inlet valve open, IVO & 351.0 & ${ }^{0} \mathrm{CA}$ \\
Exhaust valve close, EVC & 398.0 & ${ }^{0} \mathrm{CA}$ \\
Heat transfer coefficient & 15.0 & $\mathrm{~W} \mathrm{~m}{ }^{-2} \mathrm{~K}$ \\
Layer thickness & 3.0 & $\mathrm{~mm}$ \\
Piston temperature & 590.0 & $\mathrm{~K}$ \\
Cylinder head temperature & 550.0 & $\mathrm{~K}$ \\
Radiative temperature & 320.0 & $\mathrm{~K}$ \\
\hline
\end{tabular}

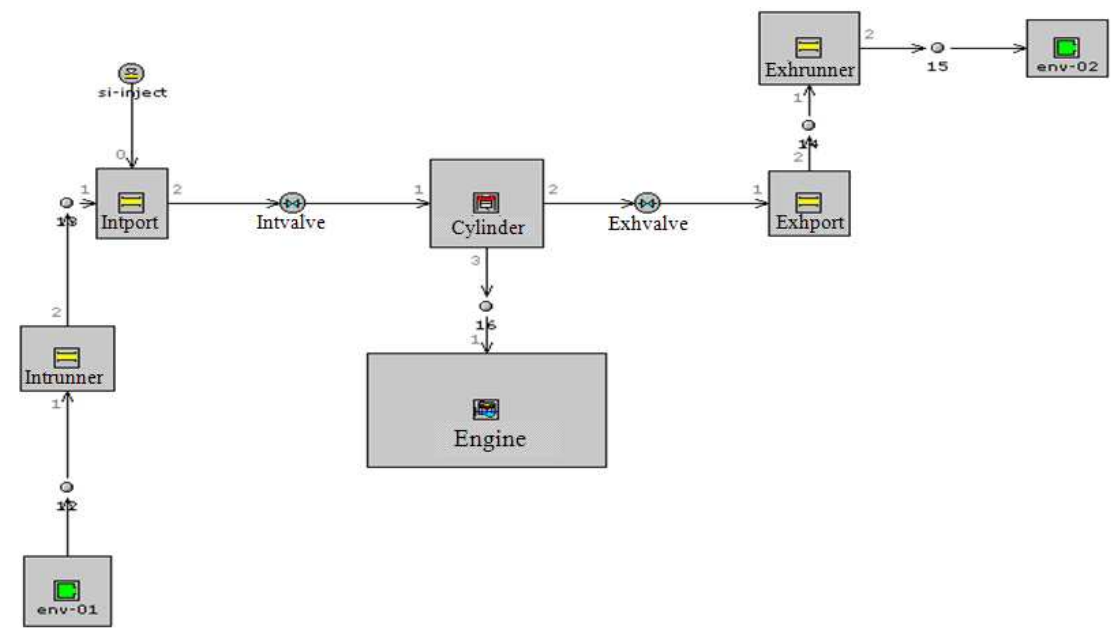

Fig. 1: Model of single cylinder port injection hydrogen fueled engine 
Finally a pipe with $0.06 \mathrm{~m}$ diameter and $0.15 \mathrm{~m}$ length connects the last flow-split to the environment. Exhaust walls temperature was calculated using a model embodied in each pipe and flow-split.

Heat transfer equations: The friction coefficient expression for smooth and rough walls is shown in Eq. 1 and 2 respectively:

$$
\begin{aligned}
& C_{f}=\frac{16}{\operatorname{Re}_{D}} \quad \operatorname{Re}_{D}<2000 ; \operatorname{Re}_{D}=\frac{v D}{v} \\
& C_{f}=\frac{0.08}{\operatorname{Re}_{D}^{0.25}} \quad \operatorname{Re}_{D}>4000 \\
& C_{f(\text { rough })}=\frac{0.25}{\left(2 \log _{10}\left(\frac{D}{2 h}\right)+1.74\right)^{2}}
\end{aligned}
$$

where, $\mathrm{Re}_{\mathrm{D}}, \mathrm{D}$ and $\mathrm{h}$ are Reynolds number, pipe diameter and roughness height respectively.

The internal wall temperature is defined as in (3):

$\mathrm{h}_{\mathrm{g}}=\frac{1}{2} \mathrm{C}_{\mathrm{f}} \rho \mathrm{U}_{\mathrm{eff}} \mathrm{C}_{\mathrm{p}} \operatorname{Pr}^{-\frac{2}{3}}$

where, $\mathrm{U}_{\mathrm{eff}}, \mathrm{C}_{\mathrm{p}}$ and $\operatorname{Pr}$ are the effective speed outside boundary layer, specific heat and Prandtl number respectively. The Prandtl number can be expressed as in (4):

$$
\operatorname{Pr}=\frac{v}{\alpha}
$$

where, $U$ and $\alpha$ are the kinematic viscosity and thermal diffusivity respectively. The heat transfer coefficient can be expressed as in (5) (Woschni, 1967):

$$
\begin{aligned}
& \mathrm{h}=3.26 \mathrm{D}^{-0.2} \mathrm{P}^{0.8} \mathrm{~T}_{\mathrm{g}}^{-0.55} \mathrm{w}^{0.8} \\
& \mathrm{w}=2.28 \mathrm{C}_{\mathrm{m}}+0.00324 \frac{\left(\mathrm{P}-\mathrm{P}_{\mathrm{m}}\right) \mathrm{V}_{\mathrm{h}} \mathrm{T}_{\mathrm{r}}}{\mathrm{P}_{\mathrm{r}} \mathrm{V}_{\mathrm{r}}}
\end{aligned}
$$

where, $\mathrm{D}, \mathrm{P}, \mathrm{P}_{\mathrm{m}}, \mathrm{T}_{\mathrm{g}}, \mathrm{V}_{\mathrm{h}}, \mathrm{C}_{\mathrm{m}}, \mathrm{V}_{\mathrm{r}}$ and $\mathrm{r}$ are the bore diameter, pressure, motored pressure, gas temperature, volume, mean piston speed, swept volume and reference crank angle respectively.

The engine heat transfer was estimated by using Woschni (1967) correlation. The rate of heat release as a function of crank angle is obtained by differentiating the cumulative heat release Weibe function (Ferguson and Kirkpatrick, 2001):

$$
\frac{\mathrm{dQ}}{\mathrm{d} \theta}=\mathrm{Q}_{\mathrm{in}} \frac{\mathrm{dx}_{\mathrm{b}}}{\mathrm{d} \theta}=\mathrm{n} \times \mathrm{a} \frac{\mathrm{Q}_{\text {in }}}{\theta_{\mathrm{d}}}\left(1-\mathrm{x}_{\mathrm{b}}\right)\left(\frac{\theta-\theta_{\mathrm{s}}}{\theta_{\mathrm{d}}}\right)^{\mathrm{n}+1}
$$

Where:

$\mathrm{Q}=$ Heat release

$\mathrm{Q}_{\text {in }}=$ Lower heating value

Therefore, the cumulative heat release fraction can be described as in (7) using a Wiebe function (Ferguson and Kirkpatrick, 2001):

$\mathrm{x}_{\mathrm{b}}(\theta)=1-\exp \left[-\mathrm{a}\left(\frac{\theta-\theta_{\mathrm{s}}}{\theta_{\mathrm{d}}}\right)^{\mathrm{n}}\right]$

Where:

$\theta=$ Crank angle in degree

$\theta_{\mathrm{s}}=$ Crank angle corresponding to initialization of heat release

$\theta_{\mathrm{d}}=$ Crank angle corresponding to the duration of burn, $\mathrm{n}$ and a are the Weibe form factor and efficiency factor having typical values of 3 and 5 respectively

\section{RESULTS}

The Air-Fuel Ratio (AFR) was varied from stoichiometric limit $(\mathrm{AFR}=34.33: 1$ based on mass where the equivalence ratio $\varphi=1.0$ ) to very lean limit (AFR $=171.65$, where $\varphi=0.2$ ) and engine speed was varied 2000-5000 rpm with $1000 \mathrm{rpm}$ interval and crank angle varied from $-40^{\circ}$ to $100^{\circ}$.

The experimental results from (Lee et al., 1995) were used for the purpose of validation of this study. Engine specifications of validated model are listed in Table 2. Engine speed and AFR were fixed at $1500 \mathrm{rpm}$ and $68.66(\varphi=0.5)$ respectively. The correlation of pressure is shown in Fig. 2. It can be seen that the distribution of pressure against the crack angle is good agreement for compression and expansion strokes while a significant deviations are observed for combustion period because of delay combustion with difference valve timing and due to few modifications that is not mentioned in (Lee et al., 1995). However, considerable coincident between the present model and experimental results can be recognized in spite of the differences in the model.

Comparison between the hydrogen and methane fuels in terms of heat transfer rate and the ratio of heat transfer to total fuel energy with respect to engine speed is shown in Fig. 3 and 4 respectively. Both of the normalized apparent and cumulative heat release rate are used as an indicator for recognizing the in-cylinder heat transfer characteristics for port injection $\mathrm{H}_{2} \mathrm{ICE}$. Effects of engine speed on the normalized apparent and cumulative heat release rate are presented in Fig. 5 and 6 respectively. 
Am. J. Environ. Sci., 6 (2): 124-129, 2010

Table 2: Specifications of the engines models

\begin{tabular}{llcl}
\hline Engine parameter & (Lee et al., 1995) & $\begin{array}{l}\text { Present } \\
\text { model }\end{array}$ & $\begin{array}{l}\text { Present } \\
\text { model unit }\end{array}$ \\
\hline Bore & 85 & 85.0 & $\mathrm{~mm}$ \\
Stroke & 86 & 86.0 & $\mathrm{~mm}$ \\
TDC clearance height & NA* & 3.0 & $\mathrm{~mm}$ \\
Piston pin offset & NA & 1.0 & $\mathrm{~mm}$ \\
Connecting rod length & NA & 150.0 & $\mathrm{~mm}$ \\
Compression ratio & 8.5 & 8.5 & - \\
Inlet valve open & 16 & 16.0 & CA (BTDC) \\
Exhaust valve open & 52 & 52.0 & CA (BBDC) \\
Inlet valve close & 54 & 54.0 & CA (ABDC) \\
Exhaust valve close & 12 & 12.0 & CA (ATDC) \\
\hline
\end{tabular}

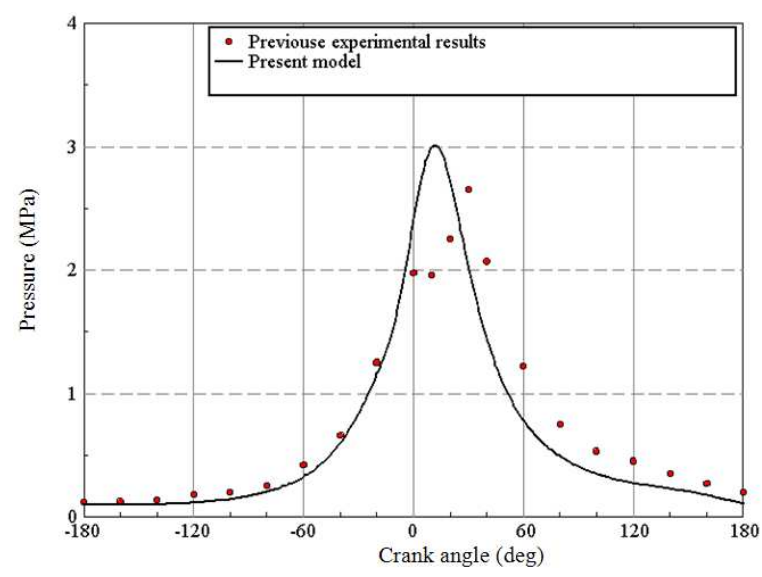

Fig. 2: Comparison between experimental results (Lee et al., 1995) and based on present engine model

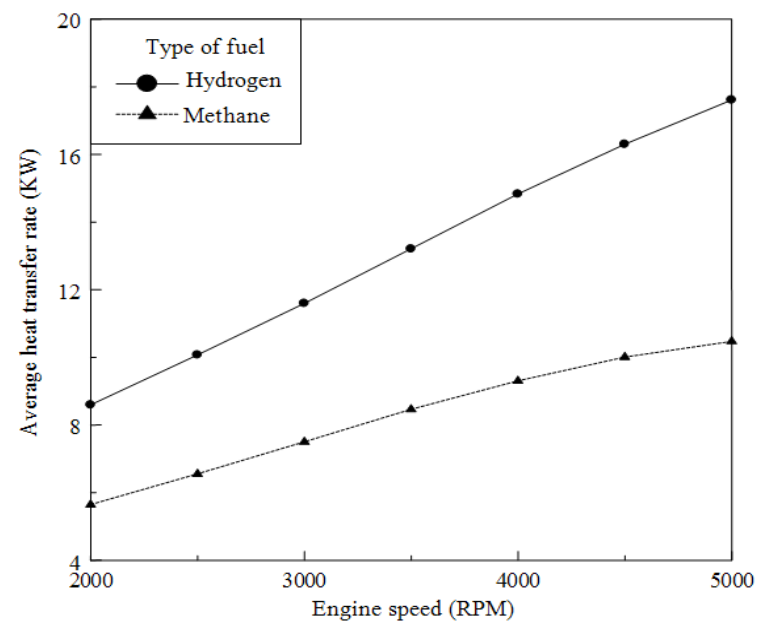

Fig. 3:Comparison between hydrogen and methane in term of heat transfer rate for equivalence ratio $\varphi=1.0$

Variation of in-cylinder pressure against engine speed for various air fuel ratios is illustrated in Fig. 7.

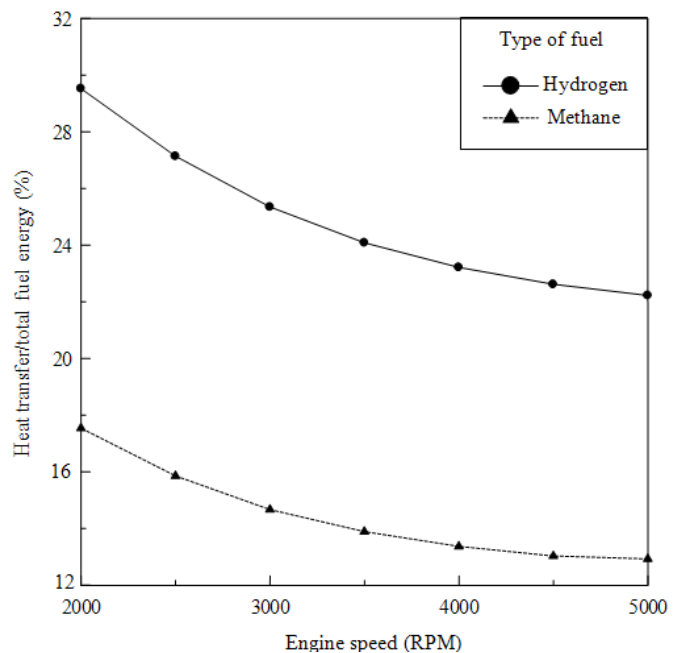

Fig. 4: Comparison between hydrogen and methane in term of percentage ratio of heat transfer to total fuel energy

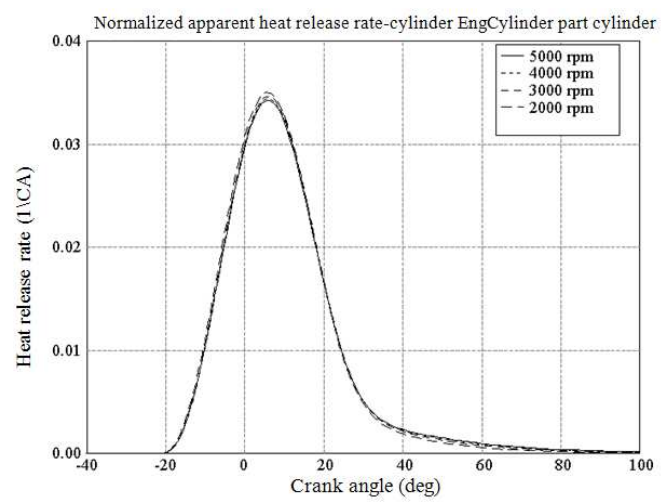

Fig. 5: Variation of apparent heat release rate with engine speed

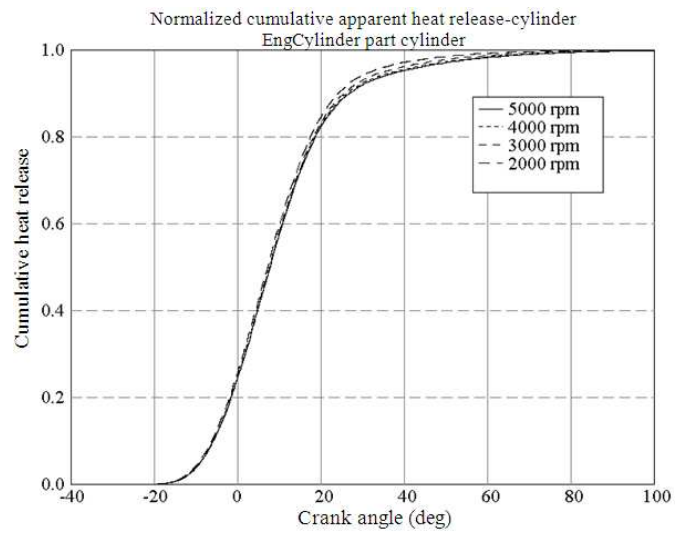

Fig. 6: Variation of normalized cumulative heat release rate with engine speed for equivalence ratio $(\varphi)=1.0$ 
Am. J. Environ. Sci., 6 (2): 124-129, 2010

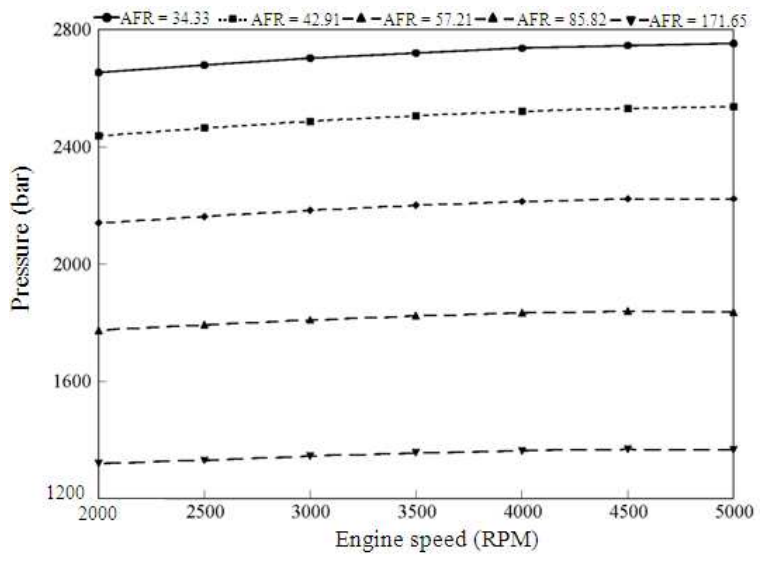

Fig. 7: Variation of in-cylinder pressure against engine speed for various air fuel ratios

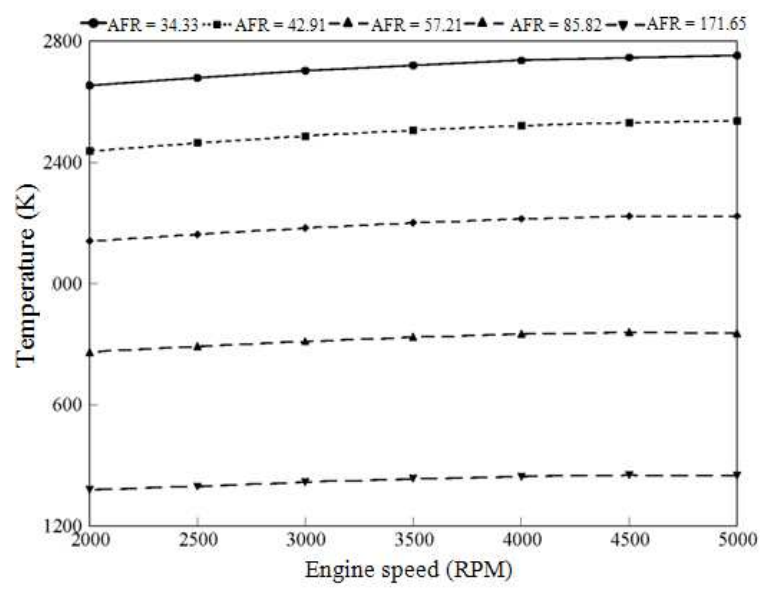

Fig. 8: Variation of in-cylinder temperature against engine speed for different AFR

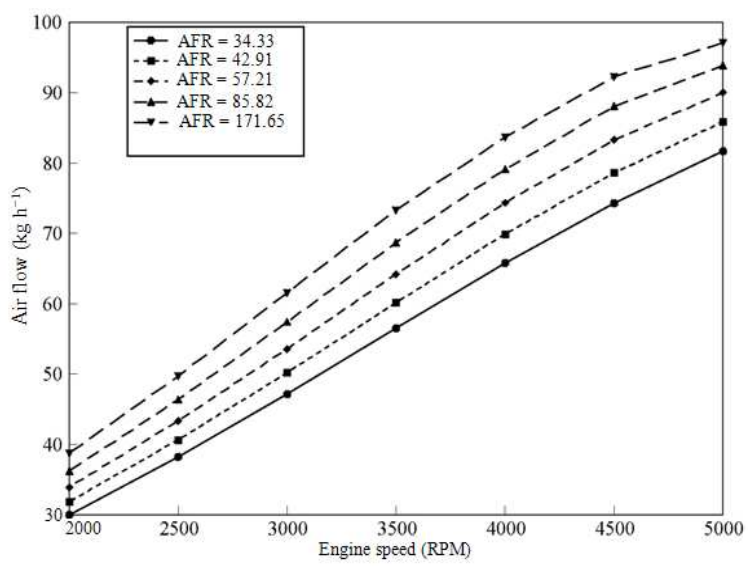

Fig. 9: Variation of in-cylinder air flow rate against for different AFR
In-cylinder pressure increased with decreasing AFR for all engine speeds due to the increase of driving force inside the cylinder. Variation of the maximum incylinder temperature against engine speed at different AFR is demonstrated in Fig. 8. In-cylinder air flow rate behavior in terms of engine speed at different AFR is represented in Fig. 9. It showed the variation of average in-cylinder air flow rate with engine speed and AFR.

\section{DISCUSSION}

From results the effect of engine speed and equivalence ratio on the in-cylinder heat transfer and flow characteristics are clarified in case of hydrogen and methane fuels. The behavior of the in-cylinder heat transfer and flow characteristics found to be governed by the energy content and forced convection effects. Forced convection effect is related to engine speed variation, while the energy content effect is related to AFR variation.

It can be seen that the heat transfer rate increases with increases of engine speed for both fuels (as shown in Fig. 3) while the ratio of heat transfer to total fuel energy decreases with engine speed (Fig. 4). The observation of the heat transfer rate behavior through the cylinder to ambient is revealed that in case of hydrogen fuel gives higher values than that of methane fuel due to the higher heating value, faster flame speed and small quenching distance. This can be used as an indicator for clarifying that the hydrogen fuel gives more heat loss compared to hydrocarbon fuel.

As shown in Fig. 5 and Fig. 6, the dependency of the normalized heat release rate on engine speed are negligible which is related to the amount of energy content in the inlet charge to combustion chamber. Besides that, the maximum heat release rate decreased with increasing engine speed. The in-cylinder pressure and temperature represents the main operating parameters for the engine which are affected by the heat transfer. The in-cylinder pressure was increased with decreasing AFR and increasing engine speed until 4000 rpm except rich mixture as shown in Fig. 7. The increment of in-cylinder pressure is increased with increases of AFR due to the presence of the less amount of energy content for inlet charge resulting less pressure from the combustion process. It can be seen that AFR is more crucial than engine speed as operational parameter for an in-cylinder pressure. The maximum range of pressure variation for various engine speeds are within 5 bars. From Fig. 8, which is presented earlier, it can be observed that the temperature increased with decreasing air fuel ratio with minor effects on engine speed. Also as engine 
speed increases the maximum in-cylinder temperature are slightly increased for all AFR. The maximum range of temperature variation for different engine speed was within $100 \mathrm{~K}$.

Behavior of the In-cylinder air flow rate is found that the air flow rate was lower at lower air fuel ratio due to blockage effect occurrence at lower AFR. This means that greater amount of hydrogen fueled was entered to the cylinder with intake charge. That's behavior is expected because of the engine speed is represented as the main driving force for the incylinder air flow rate. However, the engine speed has an imperative influencing factor on the in-cylinder air flow rate as an operating condition.

\section{CONCLUSION}

Heat transfer characteristics of in-cylinder $\left(\mathrm{H}_{2} \mathrm{ICE}\right)$ at steady state condition were presented. It was found that the effect of engine speed and AFR on pressure and temperature has a direct impact on engine performance. The results have been presented for better understanding of heat transfer characteristics of hydrogen fueled engine. The simulation results are employed to scrutinize the effect of operating parameters (such as engine speed and AFR) on the variation of in-cylinder gas flow characteristics. The results implied that AFR has a crucial effect on characteristics variation whilst engine speed has minor effects. These results would be utilized for the study of combustion process, fuel consumption, emission production and engine performance.

\section{ACKNOWLEDGMENT}

The researcher would like to thank University Malaysia Pahang for provides laboratory facilities and financial support under project no. RDU0903097. The support from International Islamic University is also greatly acknowledged.

\section{REFERENCES}

Bahram, K., D.C. Haworth and M.S. Hubler, 1994. Multidimensional port and in-cylinder flow calculations and flow vision study in an internal combustion engine with different intake configurations. SAE Paper No. 941871. http://www.sae.org/technical/papers/941871

Bakar, R.A., M.K. Mohammed and M.M. Rahman, 2009. Numerical study on the performance characteristics of hydrogen fueled port injection internal combustion engine. Am. J. Eng. Applied Sci., 2: 407-415. DOI: 10.3844/ajeassp.2009.407.415
Ferguson, C.R. and A.T. Kirkpatrick, 2001. International Combustion Engines: Applied Thermosciences. 2nd Edn., John Wiley and Sons, Inc., New York, ISBN: 10: 0471356174, pp: 384.

Kahraman, E., C. Ozcanli and B. Ozerdem, 2007. An experimental study on performance and emission characteristics of a hydrogen fuelled spark ignition engine. Int. J. Hydrogen Energy, 32: 2066-2072. DOI: 10.1016/j.ijhydene.2006.08.023

Lee, S.J., H.S. Yi and E.S. Kim, 1995. Combustion characteristics of intake port injection type hydrogen fueled engine. Int. J. Hydrogen Energy, 20: 317-322. DOI: 10.1016/0360-3199(94)00052-2

Li, G., S.M. Sapsford and R.E. Morgan, 2000. CFD Simulation of a DI Truck Engine Using Vectis. SAE Paper no. 2000-01-2940. http://www.sae.org/technical/papers/2000-01-2940

Rahman, M.M., M.K. Mohammed and R.A. Bakar, 2009a. Effect of air fuel ratio and injection timing on performance for four cylinder direct injection hydrogen engine. Eur. J. Sci. Res., 25: 214-225. http://www.eurojournals.com/ejsr.htm

Rahman, M.M., M.K. Mohammed and R.A. Bakar, 2009b. Effects of air fuel ratio and engine speed on performance of hydrogen fueled port injection engine. J. Applied Sci., 9: 1128-1134. DOI: 10.3923/jas.2009.1128.1134

Shojaeefard, M.H. and A.R. Noorpoor, 2008. Flow simulation in engine cylinder with spring mesh. Am. J. Applied Sci., 5: 1336-1343. http://www.scipub.org/fulltext/ajas/ajas51013361343.pdf

White, C.M., R.R. Steeper and A.E. Lutz, 2006. The hydrogen-fueled internal combustion engine: A technical review. Int. J. Hydrogen Energy, 31: 1292-1305. DOI: 10.1016/j.ijhydene.2005.12.001

Woschni, G., 1967. A Universally Applicable Equation for the Instantaneous Heat Transfer Coefficient in the Internal Combustion Engine. SAE Paper No. 670931. http://www.sae.org/technical/papers/670931

Yusaf, T.F., M.Z. Yusoff, I. Hussein and S.H. Fong, 2005. A quasi one-dimensional simulation of a 4 stroke spark ignition hydrogen fuelled engine. Am. J. Applied Sci., 2: 1206-1212. http://www.scipub.org/fulltext/ajas/ajas2812061212.pdf 